\title{
The Effect of Self Efficacy on Perceived Job Insecurity in the Nigerian Banking Industry: the Mediating Role of Employee Self Esteem
}

\author{
Adewale, A. Adekiya ${ }^{1 *}$, Bamidele Adepoju ${ }^{1}$, Garba, Bala Bello ${ }^{1} \&$ Oscar, Bernardes ${ }^{2}$ \\ ${ }^{I}$ Department of Business Administration and Entrepreneurship, Bayero Business School, Bayero University, Kano, Nigeria \\ ${ }^{2}$ School of Accounting and Administration of Porto - ISCAP, Polytechnic of Porto, Portugal
}

Received 18.04.2018; Received revised 17.01.2019; Accepted 20.05.2019

Available online 30.06.2019

\begin{abstract}
Based on the assumption that the construct of self-esteem should acts as a major factor in the selfevaluation model and it's often given a consideration whenever the objective is determining the nature of human behavior including the coping styles usually adopted by employees as a result of exposure to insecure job perception, this study extends on previous research by employing the use of Lazarus transactional stress theory and Korman social construction theory to present a research model which highlights employees self-efficacy as an antecedent of perceived job insecurity with employee's self-esteem acting as a mediator in this relationship. To advance our line of theoretical reasoning, we elicit responses from a total of one hundred and fifty three (153) randomly selected bankers in four major Nigerian Banks to empirically prove that employee self-esteem represents a core construct whenever the objective is centered on reducing the perception of job insecurity from the perspective of job related efficacies. Specifically, two key findings were uncovered: 1) while increase in self-efficacy will directly lead to a significant increase in self-esteem, it will however lead to an insignificant decrease in perceived job insecurity. 2) An improvement in self-esteem exercises a direct, negative and statistically significant influence on perceived job insecurity. Hence, with the view that managers and practitioners can advance their course in reducing employee's self-perceived job insecurity through self-efficacy by focusing on improving selfesteem, we conclude by proposing relevant personality based interventions in addition to those organizational and institutional based interventions which may be employed in advancing this course.
\end{abstract}

Keywords: perceived job insecurity, self-efficacy, self-esteem, mediation, banking industry.

Address of correspondence: Adewale, A. Adekiya, Department of Business Administration and Entrepreneurship, Bayero University, Kano, Nigeria Mobile Number: +2348169231070 .

Email: wallacetoks@yahoo.com

\section{Introduction}

The heightened competition among organizations has resulted in various forms of survival strategies: downsizing, restructuring, mergers, acquisitions, and introduction of new technology, as a result of the need to ensure organizational competitiveness, profit maximization and reduction in operation costs (Wellman, Huang, Ashford, Lee \& Wang, 2016; Kraja, 2015; Smith 2013). The resultant outcome of these strategies is mass employee layoff in addition to an increasing trend in global unemployment rate (Brynjolfsson \& Mc-Afee, 2012; Creed, Bloxsome \& Johnston, 2000). Eurostat (2013) pointed that statistics for full unemployment and temporality in Europe ranges between 10.6 percent and 13.7 percent respectively in 2014 while in the OECD countries, unemployment figure rose from 6 percent to 7.9 percent of the labor force in the same year with considerable variation between countries (Green, 2015). Moreso, in the United States of America, the Bureau of Labor Statistics recorded mass layoff representing more than 2 million job losses in 2008 alone with more than 7 million jobs lost since the late 1970s (Bureau of Labor Statistics, 2011). Similarly, it has been lamented by Cheng (2013) that permanent employment is increasingly being replaced by temporary or fixed-term employment contracts 
in China. Thus in line with these trends, the Nigerian Banking industry, have sacked or summarily dismissed a total of 55,000 representing 26.6 percent of the workforce in 2009 alone (Kunle, Shittu \& Kolawole, 2013). Moreso, Diamond Bank, Eco-Bank, Access Bank, Zenith Bank and Unity Bank laid off about 20.5 percent, 18.69 percent, 21.8 percent, 16.27 percent, and 7.4 percent of their permanent staff respectively in 2016 (Vanguard, August, 2016). As a result of this transformation, many workers, who are still employed, have been exposed to increasing level of selfperceived job insecurity which may be classified as feelings of uncertainty, stress and anxiety about the existence and features of their job (Chirumbolo, 2005; Borra \& Gómez-García, 2014). While it may seem quite an uphill task getting a precise estimate of the prevalence of job insecurity in the workforce, the 2016 American Psychological Association Work and Well-Being Survey reported that 38 percent of respondents agreed that job insecurity as a significant source of stress (Shoss, 2018). Several reviews and meta-analyses have documented that this phenomenon is associated with a wide range of potential negative consequences (see; Cheng \& Chan, 2008; Sverke, Hellgren, \& Na"swall, 2002, for two metaanalyses).Given this, researches have also highlights the need for understanding of what can give rise to, or prevent its occurrence (Shoss, 2018; Huang, Wellman, Ashford, Lee, \& Wang, 2016).

Considering that it has been highlighted as a perception and a subjective phenomenon that differs across individuals (see; Hartley, Jacobson, Klandermans, \& VanVuuren, 1991), then one may tend to understand it better by focusing on human subjectivity and dynamism (Smith, 2013; Keim, Landis, Pierce, Earnest, 2014; Adekiya, 2015). In this regard, some researchers have suggested core self-evaluation as reliable predictors of this perception (see; Mak \& Mueller, 2000; Naswall, Sverke, \& Hellgren, 2005). This is as a result of the fact that on one side, victims of perceived job insecurity are usually characterized by perceived uncontrollability which refers to the feeling of powerlessness an employee has toward the factors that threaten their employment (Smith, 2013). While on the other side, the ability to cope with this feelings is affected by the way people think of themselves, make sense of the world, and evaluate their available options and resources for coping (Lasdat, 2010). Though, empirical evidences have been extensively used to prove that core self-evaluations measures such as locus of control and tolerance for ambiguity are negatively associated with job insecurity (Ashford, Lee \& Bobko, 1989; Bosman \& Buitendach, 2005). However, researches that examine the influence of self-efficacy in this regard remain scanty despite its potential for determining the ability to cope with the unpredictable and uncontrollable nature of job insecurity (see; Bandura, 1986; Skaalvik \& Skaalvik, 2010; Smith, 2013). In line with this view, Greenhalgh and Rosenblatt (1984) have posited that when an employee experience low-efficacy, in addition to a corresponding decrease in powerlessness, this intensifies the experienced threat of job insecurity. Similarly, the submission by Adekiya (2015) provide support for this view by maintaining that self-perceived efficacy in critical job tasks will foster perceived employability both within the internal and external labor market.

While these may seem sufficients to provide a theoretical basis for arguing that an association exists between these two variables, researches that have examined this association in an empirical atmosphere remain scanty with rather too general or non clear-cut results. Though, the empirical study by Lasdat (2010) showed a significant relationship between these two, the variance uncovered in percentage is however relatively low considering the nature of the huge theoretical justifications that have put forward by previous studies. This may probably be due to the influence of a third variable which if investigated, may provide a clearer understanding of the mechanisms underlying the connection between them. Going by these lines of reasoning, the present study highlights self-esteem as this variable. This is as a result of the fact that research findings have demonstrated that while high self-esteem will not necessarily translate into perceived capability (Mone, Baker, \& Jeffries, 1995). High self-efficacy on the other hand is predictive of high self esteem and vice versa (Hermann, 2005), thereby making it suggestible that self-efficacy predicts self-esteem rather than self-esteem predicting self-efficacy (Hajloo, 2014). This is even more so as Krietner and Kinicki (2010) averred that individuals who want to raise self-esteem should focus more on areas where they have desirable capabilities.

Based on the fact that self-efficacy has been described as the self-perception of being able to perform certain tasks under given conditions in the face of contradicting evidence (Evers et al., 2002), and self-esteem on the other hand has been identified as individual's evaluation of self (Kohn, 1994), then it may be argued that in the context of organizational settings being characterized by insecure job positions, while employees high in self-efficacy are more likely prone to be of the view that they are capable of surviving the negative outcomes that usually precedes potential job threatening situation, and thus, sees it as a challenge rather than as a threat (Smith, 2013; Shoss, 2017), this type of optimism on the other hand, should serve as a basis of self-evaluation and assessment when making judgment about their overall worth within the organization, the rate to which they may feel that organization's survival is dependent on them, and a corresponding decrease in the rate they may tend to have perception of job insecurity (Adekiya, 2015). Nonetheless, of note is that little or no empirical evidence exists regarding the extent to which a decrease or increase in these two self-evaluation attributes can inhibit or facilitate the perception of job insecurity. Similarly, of more importance is the fact that it is not yet known, the nature of their joint effects and how are they relate with this source of job stress. Thus, our understanding of the relationship between self-efficacy and perceived job insecurity needs to address important interactive questions which may be in form of how does efficacious belief and self-esteem interplay to effect a change in self-perceived job insecurity. The hope is that outcome from this endeavor will provide insights in designing intervention strategies to counter the incidence of self-perceived job insecurity.

\section{Self-efficacy and perceived job insecurity}

Going by the conceptualization, which highlights selfefficacy as the, "beliefs in one's capabilities to mobilize the motivation, cognitive resources, and courses of action needed to meet given situational demands" (Wood \& Bandura, 1989, pp.3), it may then be highlighted as an important component of employee responses to the uncontrollability nature of job insecurity (Smith, 2013). While researchers have identified individual level differences as having the potential for gaining insight into the experience of job insecurity (Smith, 2013). These 
differences have also been found to mitigate the negative psychological effects of workplace stressors such as job insecurity (Cooper, Dewe, \& O'Driscoll, 2001). For instance, it may seem logical to conclude that the more confident an individual becomes in their ability to cope with events in organizations characterized by unstable job positions, the less likely they are to experience the perception of job insecurity because they have more confidence in ability to handle organizational changes that lead to job insecurity (Smith, 2013). In line with this view, Bandura (2005) confirmed that perceived self-efficacy affects how well individuals manage requirements and challenges including those that emanates from the work settings. To provide a relevant theoretical foundation for this, we would like to highlight Lazarus transactional stress model which posits that stressor perception is a combination of both objective stimuli and individual characteristics (Lazarus, 2001; Pierce, Gardner, Cummings, \& Dunham, 1989). The process of which results in a classification of the stressor as being a challenge, a threat, harm/loss and the accompanying behavioral or emotional responses (Cheng, 2013; Knezevic \& Knezevic, 2016). Thus, we argued in this regard that self-efficacy is a product of individual and organizational factors (nature and nurture) which may act as a determinant to the perception of job insecurity and the reaction that is exhibited by workers towards this stressor. In consistent with this view, Jimmieson et al (2004) found in their empirical study of work related self-efficacy that higher rates of self-efficacy has a direct link to reduced stress levels, and to the tendency to view workplace instability as an opportunity rather than a threat. By and large, it is presumed that self-efficacy, which is viewed in this study as the self perceived competence in work related tasks will exercise an effect on the perception of job insecurity. Following this line of thought, this hypothesis is put forward.

Hypothesis (1) there is a significant relationship between self-efficacy and perception of job insecurity.

\section{The mediating role of self-esteem}

Self-esteem refers to an individual's overall selfevaluation (Rosenberg, 1965). Thus, while self- efficacy is the perceived competence of accomplishing a particular task, self-esteem on the other hand refers to the overall evaluation of one's accomplishments, capabilities, values and possessions (Hajloo, 2014). Consistent with this view, Joubert (1990, pp.13) pointed that it is a "person's judgment of general self-worth, and a product of an implicit evaluation of self-approval or self-disapproval made by the individual". Consolidating on these, Tesser (2000) pointed that it is an evaluation process reflecting people's view of accomplishments, perceived capabilities, and values. As argued by Pierce et al. (1989) it is that selfevaluation and description made and maintained by individuals with regard to themselves. Hence, individuals characterized by high self-esteem, are also characterized by sense of personal adequacy and a belief that they have achieved need satisfaction in the past (Korman, 1966). While relating this to events in organizational settings, peirce et al. (1989) portrayed self-esteem as a selfevaluation of one's worthiness as an organizational member. In the opinion of Pierce and Gardner (2004) it reflects the self-perceived value that individuals have of themselves within their organizations. As a result of the fact that an individual's self-perceived competence and capabilities constitutes an important aspect of his overall self evaluation (Khan, Fleva, \& Quazi, 2015), and as this overall self-evaluation should aid in confronting the negative feelings associated with an unstable job market (Adekiya, 2015), then it may be suggested that self-esteem would assist in understanding the underlying mechanisms between self-efficacy and perception of job insecurity.

In consistent with this view, Afari, Ward, and Khine (2012) stated that one's self-esteem is a relevant outcome of the process of evaluating one's capabilities over a variety of applications and the subsequent learning experience associated with it. They noted that repeated success from learners can be expected to result in enhanced confidence and an expectation of further success which will hence translate to higher self valuation. Accordingly, it has been noted that individuals with high self-efficacy also report strong feelings of well-being and high self-esteem in general (see; Bandura, 1986; Smith, 2013; Wuepper, \& Lybbert, 2017). On one hand, given that Creed, Bloxsome, and Johnston (2000) have lamented that beliefs in one's capacity to change one's own situation was a major determining factor in the evaluation of one's self-esteem, and Sharp (2001) has also maintains that confidence in one's ability is likely to increase the level of well-being, including self-esteem, while on the other hand, the submission by Pierce, Gardner, Cummings and Dunham (1989) have clearly recommended that in situations where working conditions become increasingly uncertain, conflictual, demanding, with less managerial support, the perception that facilitate the development of a healthy selfesteem should be fostered, then it may be suggested that by focusing on this variable, it is likely that some of the underlying mechanism in relationship between self efficacy and perceived job would be better understood.

Furthermore, empirically generated result (e.g; Sharp, 2001) should make one concede that these two constructs are complimentary in that an increase in one would lead to an increase in the other. By focusing on the relationship among self-esteem, self-efficacy, and training performance at a Government- Funded Nuclear Operations Complex in East Tennessee, this author uncovered that trainee self efficacy is positively associated with self esteem. Also, the longitudinally designed study of 174 United States adults by Mc-Auley, Mihalko, and Bane (2005) across a 4-year period was subjected to a panel analysis and it was discovered that adults with higher levels of self-efficacy and physical activity also reported a significant higher levels of self-esteem relative to physical condition, attractive body, and strength. In other words, subjects with higher self efficacy have a significant higher tendency to engage in physical activity, which translates into perception of attractive body features, general physical condition, physical strength, and consequently, higher perception of self esteem. Thus, since an important condition necessary for mediation relationship is that the proposed mediator must in addition, to being associated with the predictor variable, be equally associated with the dependent variable (Baron \& Kenny, 1986) we propose that any increase in self-esteem as a result of perceived job efficacy would yield an optimal impact on perceived job insecurity. Consequently, this second hypothesis is put forward.

Hypothesis (2) self esteem will mediate the relationship between self efficacy and perception of job insecurity. 
Conceptual Framework:

This study contributes to the job insecurity literature by using Lazarus transactional stress model, Korman social construction theory as a framework to examine the relationship among self efficacy, self esteem and employee perception of job insecurity. The proposed relationships are depicted in Fig. 1

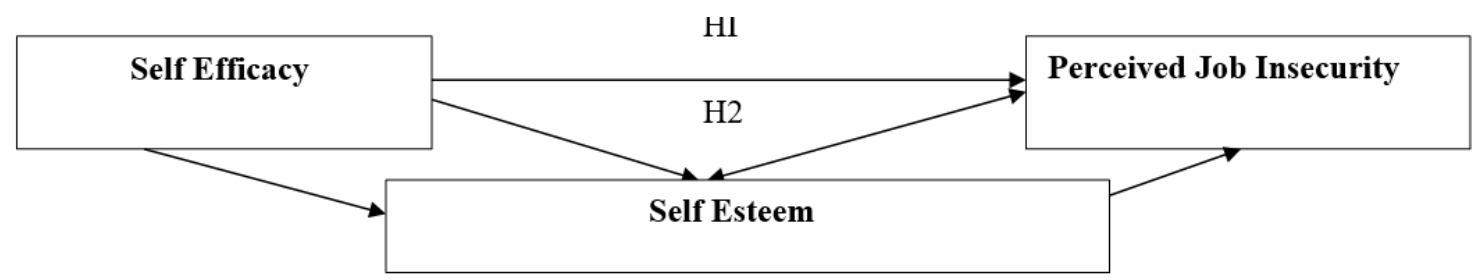

Figure.1: The conceptual framework outlining the proposed relationships between self efficacy and perceived job insecurity, self esteem and perceived job insecurity, self efficacy and self esteem, and the mediating role of self esteem in the self efficacy and perceived job insecurity relationship.

\section{Method}

\section{Design and sampling}

This research utilized the descriptive survey, using cross-sectional approach in investigating the employees of four randomly selected Nigerian commercial Banks, which have business operations in Kano metropolis. The total population of the employees in this category is five hundred and nine (509) and was adopted as the population of the study. Moreso, the multistage sampling technique was adopted in the research as a result of its precision and thoroughness (Asika, 1991). First, the four randomly selected commercial banks were divided into four strata, second, the proportionate sampling technique, which ensures that the sample size drawn from each stratum is proportionate to the total sample size, when expressed as a percentage of research total population was employed in determining the sample size appropriate for each stratum. Third, the selection of the primary sampling units from each stratum was achieved by the random sampling technique through the sampling frame that was obtained from the management of each Bank. Furthermore, the total sample size for the research was determined by drawing inference from the work of Zikmund (2005) to arrive at a sample size of two hundred and seventeen. Of the two hundred and seventeen questionnaire distributed, a total of one hundred and fifty six were retrieved. Out of these one hundred and fifty six, three copies were discarded as a result of omissions and improper completion leaving a total of one hundred and fifty three (153) which were consequently employed in data analysis thereby indicating a total response rate of $70.5 \%$. A more detailed description of the sample can be found in Table 1 .

The administration of items was carried out among the employees of selected banks in the banking premises during their working hours. In this regard, an approval was first sought from the management of the highlighted three commercial Banks. Also, the target populations involved in the study were informed that they are free to withdraw from the study at any time as it may be deemed fit. It was made clear that there will be no financial or any other form of gain from their participation. In order to adhere to principles of confidentiality, they were not required to sign any form of consent form as their decision for voluntary participation was interpreted as informed consent. Overall, it took each employee an average of five days to provide all information as requested.

\section{Measures}

Perceived Job Insecurity: the items on perceived job insecurity were adopted from Hellgren, Sverke, and Isaksson (1999), Kurhnet and Vance (1992). It consists of nine (9) items that asks questions, ranging from "I believes that I can keep my present job as long as I want", to "in the event I loss this job, I believe I can easily get another comparable job in a similar organization". For the current sample, a Cronbach alpha value of .801 was obtained.

Self Efficacy: self efficacy was measured by 9 items adopted from Sherer, Maddux, Mercandante, PrenticeDunn, Jacobs, and Rogers (1982) self-efficacy Scale (SES) which was primarily developed for clinical and personality research and later adopted in organizational settings (Iman, 2007). From the results obtained through samples of University Students and Managers, Chen, Greene, and Crick (1998) reported internal consistencies that range between .88 to .91 in a two separate studies. To ensure that the nine items adopted suit the requirements of the context in this study, they were modified to reflect the work related domain, which is the focus of this study. This scale had a cronbach alpha value of .706 for this study. Sample items include "When I make work related plans in this organization, I am certain I can make them work", "I avoid trying to learn new things when they look too difficult for me", etc.

Self Esteem: the Coopersmith Self-Esteem Instrument was adopted as a measured of self-esteem after necessary adjustments as per the requirement of the socio cultural environment in context. The instrument was among the best known and most widely used of the self-esteem measures and its brief, easily scored, reliable, and stable, and possessed enough reliability and validity for use in research (Peterson \& Austin, 1981). Additionally, the consulting Psychologists Press, Inc. (1989) reported that it has been validated by many researchers from a wide range of geographical locations. For example, a Cronbach Alpha value of .849 was obtained by a professional statistician at the University of Tennessee (Sharp, 2001). In this current sample, the Cronbach alpha is .710. sample items here ranges from "things usually don't bother me in this organization", to "in this organization, I can make up my mind without too much trouble".

Meanwhile, as a result of the minor alteration that was effected on the original version of the above mentioned items particularly the self-efficacy and self-esteem scale, it was considered imperative to ascertain the validity of the modified version by carrying out a pilot testing. In line 
with the outcome of this study, both item fifth and sixth on the scale were rephrased and made more understandable before being adopted in the main study. All the items employed in this study were presented in a form through which respondents are expected to respond by showing their degree of agreement or disagreement on a five point Likert scale.

\section{Control Variable}

Based on the importance of including control variables which are likely to be associated with outcome variables (Becker, 2005). We include gender, age, educational level, and banks. This is a result of the fact that perceived job insecurity is likely to be more prevalent among younger employees (Keim et al. 2014), and research on job insecurity (see; Chen \& Chan, 2008; Richter, 2011), have found gender and educational differences in the level of job insecurity. In addition, as there may be differences in culture and leadership among the four banks which may contribute to significant difference in the perception of job insecurity, bank was also included. Gender was included in (0 females, 1 males), age was included in (years), while educational level was included in (1 Senior School Certificate, 2 Ordinary National Diploma, 3 first degree, and 4 post graduate degree) while bank was included in (1 Zenith bank, 2 United bank for Africa, 3 Skye bank, 4 Guarantee Trust bank).

Analysis

The Pearson Product Moment Correlation was used in determining the strength of association among the variables while the Process Macros by Preacher and Hayes (2013) was utilized as a tool of analysis for testing the mediating hypothesis that was earlier put forward. This is in line with the recommendation from Mackinnon, Lockwood, Hoffman, West, and Sheets (2002) who argued that this approach allows for more valid conclusions as it does assume the indirect effect is normally distributed. All data processing was carried out by using the statistical package for social sciences (SPSS) 20th edition.

\section{Results}

Concerning the normality statistics of the data in the study, Skewness and Kurtosis values were within the acceptable threshold of \pm 2 for normal distribution of scores (Norusis, 2004). Also, the correlation matrix for main variables in addition to means, standard deviation and cronbach alpha statistics are displayed inTable 2 .

Table 2 displays the correlation among the variables. As expected, self efficacy correlated with self-esteem $p=.000$ $(\mathrm{p}<.05)$. Also, self-esteem correlated with perceived job insecurity $\mathrm{p}=.000(\mathrm{p}<.05)$. Surprisingly, there is absence of any significant relationship between self-efficacy and perceived job insecurity which suggests that having high self-efficacy may not necessarily lead to a decreased level of perceived job insecurity.

Table 1. Demographic Characteristics of Respondents

\begin{tabular}{llcc}
\hline \multicolumn{1}{c}{ Items } & Category & Frequency & Percentage \\
\hline Gender & Male & 99 & 64.7 \\
& Female & 54 & 35.3 \\
Marital Status & Single & 53 & 34.6 \\
Age & Married & 100 & 65.4 \\
& 20-25 years & 13 & 8.5 \\
& 26-31 years & 61 & 39.9 \\
& 32-37 years & 58 & 37.9 \\
& 38-43 years & 17 & 11.1 \\
Education & 44 years & 1 & 2.6 \\
& above & 1 & 7 \\
& Senior School & 15 & 9.8 \\
& Cert & 79 & 51.6 \\
Occupational & Ordinary & 53 & 37.9 \\
& Diploma & 51 & 33.3 \\
& First Degree & 84 & 54.9 \\
& Post Graduate & 15 & 9.8 \\
& Junior Staff & 3 & 2 \\
& Middle Level & & \\
& Staff & & \\
& Senior Staff & & \\
& Management & & \\
& Staff & & \\
\hline
\end{tabular}

Notwithstanding, as it has been suggested by Shrout and Bolger (2002) that in the event there is no significant relationship between the independent and dependent variable, one could move forward to the next step of analysis provided there is good theoretical background about their relationship, a test of mediation was carried out. Prior to embarking on this process, a multicollinearity test, of the independent variable self efficacy, and mediated variable, self esteem was carried out (Cohen, Cohen, West \& Aiken, 2003). Consequently we obtained a variance inflated factor (VIF) of 1.237 for both self efficacy and self esteem while a tolerance value of .808 was also obtained for the two constructs. Since the variance inflated factor is less than 2 (Hair, Black, Babin \& Anderson, 2010) while tolerance value is quite larger than the recommended value of .10 (Koop, 2005) it can be deduced that there is no serious multicollinearity among the variables. Similarly, Durbin-Watson statistic is 1.828 which is within the acceptable range of 1.5 and 2.5 (Norusis, 2004).

Table 2. Means (M), Standard Deviations (SD), and Correlations for the Study Variables

\begin{tabular}{lcccccc}
\hline & $\mathrm{M}$ & $\mathrm{SD}$ & $\mathrm{a}$ & 1 & 2 & 3 \\
\hline 1Self Efficacy & 4.1125 & 3.7098 & .706 & 1 & & \\
$\mathrm{~N}$ & & & & 153 & & \\
2 Self Esteem & & & & $.438^{* *}$ & 1 & \\
Sig (2 tail) & 3.64576 & 4.9871 & 710 & .000 & & 1 \\
$\mathrm{~N}$ & & & & 153 & 153 & \\
3 PJI & & & & -.126 & $-.295^{\circ *}$ & \\
Sig (2-tail) & 2.66302 & 4.1986 & .801 & .121 & .000 & 153 \\
N & & & & 153 & & 153 \\
\hline
\end{tabular}


The effect of self efficacy on perceived job insecurity

Table 3: Path Analysis of the Relationship among the Variables

\begin{tabular}{|c|c|c|c|c|c|c|}
\hline & Coefficient & SE & $\mathrm{t}$ & sig & LLCI & ULCI \\
\hline \multicolumn{7}{|l|}{ step 1} \\
\hline 1 (constant) & 178505 & 4.2482 & 4.2019 & .000 & 9.4556 & 26.2455 \\
\hline Self efficacy & .5073 & .0879 & 5.7744 & .000 & .3337 & 6809 \\
\hline Gender & -.5361 & .9125 & -.5875 & .557 & -2.3392 & 1.2671 \\
\hline Age & .5696 & .5029 & 1.1325 & .259 & -.4243 & 1.5635 \\
\hline Edu & -.0943 & .6743 & -.1399 & .889 & -.1 .4268 & 1.2382 \\
\hline Bank & .4326 & .5510 & .2311 & .841 & -2.3212 & 1.3672 \\
\hline \multicolumn{7}{|l|}{ Step 2} \\
\hline (constant) & 38.1931 & 5.1919 & 7.3563 & .000 & 27.9326 & 48.4535 \\
\hline Self esteem & -.3310 & .0950 & -3.4858 & .006 & -.5186 & -.1433 \\
\hline self efficacy & .0048 & .1123 & .0431 & .9657 & -.2172 & .2269 \\
\hline Gender & .2620 & 1.0553 & .2482 & .8043 & -1.8236 & 2.3475 \\
\hline Age & .6349 & .5835 & 1.0881 & .2783 & -.5182 & 1.7881 \\
\hline Edu & -1.4957 & .7790 & -1.920 & .0568 & -3.0351 & .0437 \\
\hline Bank & .1174 & .6714 & .4536 & .0436 & -3879 & 1.910 \\
\hline \multicolumn{7}{|l|}{ Step 3} \\
\hline (constant) & 29.3854 & 3.8689 & 7.5954 & .000 & 21.7413 & 37.0296 \\
\hline Self efficacy & -1632 & .1048 & -1.5580 & .1213 & -.3702 & .0438 \\
\hline
\end{tabular}

The output from the mediation analysis is presented in Table 3, 4, and 5. In the first step of the analysis displayed in table 3 , the regression of independent variable, self efficacy on mediating variable self esteem was significant, $\mathrm{b}=.5073, \mathrm{p}=.000 \quad(\mathrm{p}<.005)$ while controlling for gender, age, education and banks.

Table 4. Indirect Effect of Self Efficacy on Perceived Job Insecurity

\begin{tabular}{cccc}
\hline Effect & Boot SE & Boot & Boot ULCI \\
\hline $\mathbf{- . 1 6 8 8}$ & .0552 & -.3005 & -.0773 \\
\hline Note: $\mathrm{SE}=$ Standard Error, $\mathrm{Z}=$ Sobel test \\
\multicolumn{5}{l}{} \\
\multicolumn{5}{l}{ Table 5. Normal Theory Test for Indirect Effect } \\
\hline Effect & Boot SE & $\mathrm{Z}$ & $\mathbf{p}$ \\
\hline-.1679 & .0569 & -2.9520 & .0032 \\
\hline Note $: \mathrm{SE}=$ Standard Error $\mathrm{Z}=$ Sobel test
\end{tabular}

In the second step, it is shown that the mediating variable, controlling for the independent variable was significant, $\mathrm{b}=-.3310, \mathrm{p}=.0 .006 \quad(\mathrm{p}<.005)$ while the independent variable was not significant. Further, the third step shows that the direct effect of self-efficacy in the model was not significant, $b=-.1632, p=.1213$ ( $p>.005)$. Thus, as the a \& b path coefficients are both statistically significant and pointing towards the direction predicted, this is an indication of evidence in favor of mediation. Using bias-corrected bootstrapping with 1,000 re-samples, it can be observed in table 4 that the indirect effect of self- efficacy on perceived job insecurity is -.1688 with a $95 \%$ confidence interval -.3005 to -.0773 . Hence, since the $95 \%$ confidence interval does not include 0 , we conclude that the indirect effect is statistically significant, and full mediation is supported. In addition, the result of the Sobel test displayed in table 5 indicates that a full mediation $Z=$ $.1679, p=.0032$. Below in figure 2 is a path diagram of this model.

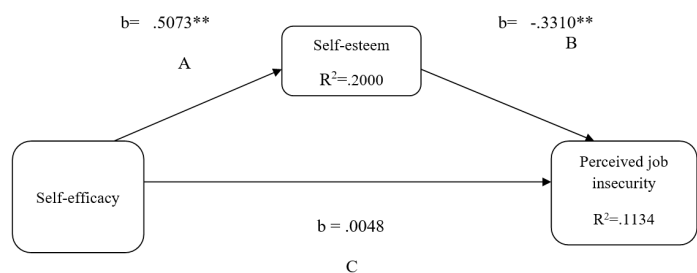

Figure 2. Path diagram of the mediation model of self-esteem as an intervening variable between self-efficacy and selfesteem

\section{Discussion}

Based on the assumption that self-perception of job insecurity may result in numerous negative consequences for the concerned individual in addition to the organization where they work (see; Cheng \& Chan, 2008; Podsakoff, LePine, \& Le-Pine, 2007), the need for more research on factors that may aid its prevention or lead to a decrease in its consequences have been highlighted by several 
researchers (Sverke \& Hellgren, 2002; Richter, Tavfelin, \& Sverke, 2018). For instance, studies (e.g. Chirumbolo, 2005) have investigated organizational factors: job satisfaction and organizational commitment in this regard and others such as Cheng and Chan (2008) have investigated employability and job dependence, while Richter (2011) have focused on age and occupational tenure. To date however, limited attention has been devoted to the potential role that cognitive factors such as self-esteem and self-efficacy may play in the development of self-perceived job insecurity. In the present investigation, this limitation is addressed by identifying the relationship between self-efficacy and perceived job insecurity while also providing proofs on the role of selfesteem as an underlying mechanism through which the former works to exercise an effect on the later. Thus, our study contributes to the literature on how the perception of job insecurity can be reduced through the perception of self- efficacy, and the" how" and "why" concerning this process. Accordingly, we found that there is no significant relationship between self-efficacy and perceived job insecurity which makes us to decline in the acceptance of hypothesis (1). Nevertheless, while it is a laid down procedure in some statistical approaches that a direct relation is a necessary condition in order for mediation to be tested (see; Baron \& Kenny, 1986), this approach by Baron and Kenny (1986) has become a subject of controversies, with newer approaches concluding that test of mediation can be carried out in the absence of an initial direct relationship (Shrout \& Bolger, 2002; Richter et al, 2018). Consequently, we embarked on this analysis of which some remarkable results were uncovered.

In line with our expectation, results did provide a support for the mediating influence of self- esteem in that the indirect relationship between self-efficacy and perceived job insecurity was significant with the inclusion of self-esteem as an intervening variable (H2). More specifically, we found that self-efficacy exercise a significant and positive influence on self esteem, and that this positive influence has a consequent negative influence on the perception of job insecurity. This was confirmed by the bootstrapping analysis in table (4) and the Sobel test displayed in table (5). Though, while the result relating to insignificant effect of self-efficacy on perceived job insecurity fails to follow the prediction of transactional stress model (Lazarus, 2001) which highlight factors of personality differences as a determinant for perceiving unstable job situations either as a threat or a challenge, the result relating to the intervening influence of self-esteem in this relationship is in full support of this prediction. In as much as it may be theoretically sound to suggest a significant direct relationship between self-efficacy and perceived job insecurity, the lack of support for this kind of relationship in this study could be due to the influence of some unknown moderators which acts as a boundary in which the former exercise an effect on the later. Another probable reason could be the existence of other mediating variable apart from self esteem in which the effects of these variables may cancel out each other, and resulting in a non-significant direct relationship (Richter et al, 2018). Other reason is that the relationship could be non-linear, and rather follows a U-shape pattern where different level of self-efficacy exercise differing direct influence on perceived job insecurity (Selenko, Mäkikangas, Mauno, \& Kinnunen, 2013). By and large, our result in this study gives an evidence of full mediation meaning that all the relationship between self-efficacy and perceived job insecurity is transmitted through the mediating variable, self-esteem. Thus, the above finding aside from being in line with the theoretical assumption by Lasdat (2010) also share similar view with the longitudinal study by Kinnunen, Feldt, and Mauno (2003) where it was discovered that low self-esteem can foster increased feelings of perceived job insecurity and vice versa. Hence, the higher employees are of perceived self capability for executing job related tasks, the more they are of the perception of a worthy member of the organization, and the less is the tendency for the perception of job insecurity. Thus, regardless of any real job threatening situation, if self-efficacy enhancement intervention strategies such as training and development program, empowerment, positive feedback and social support (Filippin \& Paccagnella, 2012; Wuepper \& Lybbert, 2017), are targeted at improving employee self-esteem, it is likely that such intervention will lead to a reduction in the perception of job insecurity.

\section{Limitations and suggestion for further research}

First, the theoretical foundation upon which the supposition of self-efficacy as a predictor of perceived job insecurity is grounded, hinges on the assumption that highly self-efficacious individuals are likely to exhibit a higher job performance which would subsequently lead to a higher self-esteem through a consist and positive feedback (Wuepper, \& Lybbert, 2017). However, studies have discovered that the ability of self-efficacy to elicit higher performance varies according to task complexity (see; Judge, Shaw, Jackson \& Rich, 2007). Specifically, these authors discovered that self-efficacy predicted performance in jobs or tasks of low complexity but not those of medium or high complexity. Hence since the highly stressed induced and task complex working environment of the Nigerian banking industry was the focus in this study, potential researchers are invited to replicate our model in sectors or organizations where job tasks are less complex. Second, potential researchers are also encouraged to take stride in determining the yet to be discovered mediators which may have been responsible for the insignificant relationship uncovered between selfefficacy and perceived job insecurity. Lastly, as studies limited to cross-sectional data provides no inference for causality (Mackinnon, Fairchild, \& Fritz, 2007), future research may therefore benefit by employing the longitudinally or experimentally designed approach in investigating the model in this study.

\section{Implications for theory and practice}

Theoretically, this study contributes to perceived job insecurity literature by establishing a link between the combination of self-efficacy and self-esteem on one side, and perceived job insecurity on the other side. Specifically, it aids in increasing our understanding of the mechanism through which self-efficacy exercise an effect on perceived job insecurity. Additionally, it has provided a robust foundation for the behavioral plasticity theory by Brockner (1988) where it was declared that people with low selfesteem are likely to react more to external cues than their counterparts who are more in this attribute. Thus, in the context of self perceived job insecurity, people with high self-esteem may engage in problem-focused coping, see this as a threat, rather than as challenge (Hui \& Lee, 2000). Additionally, the finding is grounded on social construction theory (Korman, 1970), which stressed the importance of individual's evaluation of self, on the ability 
to confront the numerous multi-dimensional challenges associated with daily activities. It follows that individual characteristics, conditions, and resources also play a major part in employees' sense of insecurity. Further, our research answers the call for further research by (e.g; Sverke \& Hellgren, 2002; Richter, Tavfelin, \& Sverke, 2018) on factors that can eliminate or reduce the perception of job insecurity.

Practically, since our finding have demonstrated that the perception of job insecurity is less severe in cases where employee's self-efficacy, and perception of selfworth improves, managers must pay attention to enhancing employee self-efficacy. This could be done by adhering to the principles of round peg in a round hole through appropriate psychological testing during recruitment exercise and by ensuring that workers are made to undergo a periodic training and development programs with a view to equip them with the required skills for enhancement of self-efficacy. Managers should also embrace the use of positive feedback, words of praise, recognition, delegation of duties, and decision making authority while dealing with employees in that such gestures may likely lead to an improved self evaluation and consequently, self-esteem.

In a global business environment, in which business organizations have to operate in an uncertain atmosphere, coupled with an increasing threat to job positions in these organizations, the perception of job insecurity have transcend into a phenomenon that cut across different occupational contexts and countries which seems to suggests that perceived job insecurity is now a stressor for a large chunk of the global work-force (Shoss, 2018). While this study used a sample of bank employees in the Nigerian industry, the investigated relationship is however not in uniqueness to this industry alone or to the Nigerian business context but meant to be generalized to other geographic locations and industries. In view of this, a study with this model should be replicated in other occupational and geographical context to enhance the validation of the results here. Conclusively, there is need to recognize the implication that feelings of persistent insecure job perception poses for the organization, family, and the society at large. Hence, institutional policies such as labor law against undue dismissal and a social security system that emphasizes benefit packages for unemployed individuals should also be devised with the aim of reducing or eliminating its occurrence.

\section{Declaration of Conflicting Interests}

No conflict of interest whatsoever is declared in this article.

\section{Acknowledgement}

An appreciation is extended to the management of Zenith Bank Nigeria, United Bank for Africa, Nigeria, Guaranty Trust Bank Nigeria, and Skye Bank Nigeria for ensuring the availability of all relevant data necessary to enhance the accomplishment of this research.

\section{References}

Adekiya, A.A. (2015). Perceived job insecurity: Its individual, organizational and societal effects. European Scientific Journal, 1, 100-118.

Afari, E., Ward, G., \& Khine, M.S. (2012). Global self-esteem and self-efficacy correlates: relation of academic achievement and self-esteem among Emirati students. International Education Studies, 5, 49-57.

Ashford, S. J., Lee, C., \& Bobko, P. (1989). Content, causes, and consequences of job insecurity: A theory-based measure and substantive test. Academy of Management Journal, 32, 803-829. Doi: 10.2307/256569.

Asika, N. (1991). Research Methodology in the Behavioral Sciences. Lagos, Nigeria: Longman Nigeria plc.

Bandura, A. (1986). Social Foundations of Thought and Action. New Jersey: Prentice Hall.

Barron, R. M., \& Kenny, D. A. (1986). The moderatormediator variable distinction in social psychological research: Conceptual, strategic, and statistical considerations. Journal of Personality and Social Psychology, 51, 1173-1182.

Becker, T. E. (2005). Potential problems in the statistical control of variables in organizational research: A qualitative analysis with recommendations. Organizational Research Methods, 8, 274-289. doi:10.1177/ 1094428105278021.

Bosman, J., Rothmann, S., Buitendach, J.H. (2005). Job insecurity, burnout and work engagement: The impact of positive and negative affectivity. SA Journal of Industrial Psychology, 31, A199. doi:10.4102/sajip.v31i4.199

Brynjolfsson, E. \& McAfee, A. (2012). Big Data: The management revolution. Harvard Business Review 90(10), $60-6,68,128$

Brockner, J. (1988). Self-Esteem at work: Research, theory, and practice. Lexington, MA: Lexington Books.

Cheng, G., \& Chan, D. (2008). Who suffers more from job insecurity? A meta-analytic review. Applied Psychology: An International Review, 57, 272-303. doi:10.1111/j.1464-0597.2007.00312.x.

Cheng, T. (2013). Revisiting the buffers of job insecurity: Investigating new buffering factors between perceived job insecurity and employee outcomes. Academic dissertation submitted to Jyväskylä Studies in Education, Psychology and Social Research 485. Jyväskylä University Printing House, ISBN 978-951-39-5472-7.

Chirumbolo, A. (2005). The influence of job insecurity on job performance and absenteeism: The moderating effect of work attitudes. Journal of Industrial Psychology, 31, 6571.

Cohen, J., Cohen, P., West, S.G., Aiken, L.S. (2003). Applied Multiple Regression/ Correlation Analysis for the Behavioral Sciences (3rd Ed.). Mahwah, NJ: Lawrence Erlbaum Associates.

Consulting Psychologists Press, Inc. (1989). Self-esteem inventories, Stanley Coopersmith, Ph.D. Palo Alto, California.

Cooper, C.L., P.J. Dewe, and M. O'Driscoll (2001) Stress and Work Organizations: a review and critique of theory, research and applications. California: Sage.

Creed, P.A., Bloxsome, T.D., \& Johnston, K. (2000). Selfesteem and self-efficacy outcomes for unemployed individuals attending occupational skills training programs. Retrieved from https://researchrepository.griffith.edu.au/bitstream/handle/10072/4013/15 511.pdf

De Witte, H., \& Naswall, K. (2003). 'Objective' vs 'subjective' job insecurity: Consequences of temporary work for job satisfaction and organizational commitment in four European Countries. Economic and Industrial Democracy, 24, 149-188. Doi: $10.1177 / 0143831$ X03024002002.

Eurostat (2013). European Employment Strategy Available at: http://ec.europa.eu/.

Evers, W. J., Brouwers, A., \& Tomic, W. (2002). Burnout and self $\square$ efficacy: A study on teachers' beliefs when implementing an innovative educational system in the 
Netherlands. British Journal of Educational Psychology, 72(2), 227-243.

Filippin, A., \& Paccagnella, M. (2012). Family background, self-confidence and economic outcomes. Economics of Education Review, 31 (5), 824-834

Green, F. (2015). Unpacking the misery multiplier: How employability modifies the impacts of unemployment and job insecurity on life satisfaction and mental health. Journal of Health Economics, 30, 265-276.

Greenhalgh, L., \& Rosenblatt, Z. (1984). Job insecurity: Toward conceptual clarity. Academy of Management Review, 9, 438-448.

Hair, J. F., Black, W. C., Babin, B. J., \& Anderson, R. E. (2010). Multivariate data analysis. Pearson, NJ: Pearson Education Inc.

Hajloo, N. (2014). Relationships between self-efficacy, selfesteem and procrastination in undergraduate Psychology students. Iranian Journal of Psychiatry and Behavioral Sciences, 8, 42-9.

Hartley, J., Jacobson, D., Klandermans, B., Van-Vuuen, T. (1991). Job Insecurity: Coping with Jobs at Risk. London: Sage.

Hayes, A. F., \& Preacher, K. J. (2013). Conditional process modeling: Using SEM to examine contingent causal processes. In G. R. Hancock and R. O. Mueller (Eds.) Structural equation modeling: A second course (2ndEd). Information Age Publishing.

Hellgren, J. \& Sverke, M. (2003). Does job insecurity lead to impaired well-being or vice versa? estimation of cross lagged effects using latent variable modeling. Journal of Organizational Behavior, 24, 215-236.

Hellgren, J., Sverke, M., \& Isaksson, K. (1999). A twodimensional approach to job insecurity: consequences for employee attitudes and well-being. European Journal of Work and Organizational Psychology, 8, 179-195. doi: 10.1080/135943299398311.

Hermann, K.S. (2005). The influence of social self-efficacy, self-esteem, and personality differences on loneliness, and depression [Dissertation]. Columbus, Ohio: The Ohio State University, Department of Psychology.

Hui, C., \& Lee, C. (2000). Moderating effects of organizationbased self-esteem on the relationship between perception of organizational uncertainty and employee response. Journal of Management, 26 (2), 215-232.

Joubert, C.E. (1990). Relationship among self-esteem, psychological reactance, and other personality variables. Psychological Report, 66, 1147-1151.

Jimmieson, N. L., Terry, D. J., \& Callan, V. J. (2004). A longitudinal study of employee adaptation to organizational change: the role of change-related information and change-related self-efficacy. Journal of Occupational Health Psychology, 9(1), 11.

Judge, T.A., Shaw, J.C., Jackson, C.L., \& Rich, B.S.C. (2007). Self-efficacy and work-related performance: The integral role of individual differences. Journal of Applied Psychology, 92, 107-127.

Khan, A., Fleva, E., \& Qazi, T. (2015). Role of self-esteem and general self-efficacy in teachers' efficacy in primary schools. Psychology, 6, 117-125. doi: 10.4236/psych.2015.61010

Kinnunen, U., Feldt, T., \& Mauno, S. (2003). Job insecurity and self-esteem: Evidence from cross-lagged relations in a 1-year longitudinal sample. Personality and Individual Differences, $\quad 35$, 617-632. doi: 10.1016/S01918869(02)00223-4.

Kohn, A. (1994). The truth about self-esteem. Phi Delta Kappan, 76, 272-283.

Koop, G. (2005). Analysis of Economic Data. (Second Edition) Southern Gate, Chichester, John Wiley \& Son.

Korman, A. K. (1966). Self-esteem variable in vocational choice. Journal of Applied Psychology, 50, 479-486.
Korman, A. K., (1970). Toward a hypothesis of work behavior. Journal of Applied Psychology, 54, 31-41.

Knežević, J., \& Knežević, M. (2016). The development of self structure coping. Interdisciplinary Description of Complex Systems 14(2), 246-252.

Kinicki, A \& Kreitner, R. (2010). Values, attitudes, job satisfaction, and Counterproductive behavior. Organizational behavior, New York: Mc-Graw Hill Irwin.

Kuhnert, K.W., \& Vance, R.J. (1992). Job insecurity and moderators of the relation between job insecurity and employee adjustment. In Quick JC, Murphy LR, \& Hurrell JJ Jr. (Eds.) Stress and Well-being at Work, Washington: APA.

Kunle, A.O., Shittu, A.K., \& Kolawole, A. J. (2013). Impact of job insecurity, role perception and self efficacy on bankers' effective wellbeing. IOSR Journal Of Humanities And Social Science, 1, 59-67.

Lasdat, L. (2010). To what extent do core self-evaluations and coping style influence the perception of job insecurity? Retrieved https://www.tandfonline.com/doi/abs/10.1080/1359432X. 2013.800678

Lazarus, R. S. (2001). Emotion and adaptation. New York, NY: Springer.

MacKinnon, D. P., Lockwood, C. M., Hoffman, J. M., West, S. G., \& Sheets, V. (2002). A comparison of methods to test mediation and other intervening variable effects. Psychological Methods, 7, 83-104. doi: 10.1037/1082989X.7.1.83

Mackinnon, D. P., Fairchild, A. J., \& Fritz, M. S. (2007). Mediation Analysis. Annual Review of Psychology, 58, 593-614. doi: 10.1146/annurev. psych.58.110405.085542.

Mak, A. S., Mueller, J. (2000). Job insecurity, coping resources and personality dispositions in occupational strain. Journal of Work \& Stress, 14,312-328

McAuley, E., Mihalko, S., \& Bane, S. (1997). Exercise and self-esteem in middle-aged adults: multidimensional relationships and physical fitness and self-efficacy influences. Journal of Behavioral Medicine, 20, 67-83.

Mone, M.A., Baker, D.D., \& Jeffries, F. (1995). Predictive validity and time dependency of self-efficacy, self-esteem, personal goals, and academic performance. Educational and Psychological Measurement, 55, 716-27.

N"aswall, K., Sverke, M., \& Hellgren, J. (2005). The moderating role of personality characteristics on the relationship between job insecurity and strain. Work and Stress, 19(1):37-49

Norusis, M. (2004). SPSS 13.0 Guide to data analysis. Upper Saddle-River, N.J.: Prentice Hall, Inc.

Peterson, C., \& Austin, J. T. (1981). Coopersmith self-esteem inventories. The mental measurements yearbook (9th ed.). Lincoln NE: Buros Institute.

Pierce, J. L., Gardner, D. G., Cummings, L. L., \& Dunham, R. B. (1989). Organization-based self-esteem: Construct definition measurement and validation. Academy of Management Journal, 32, 622-648.

Podsakoff, N. P., LePine, J. A., \& LePine, M. A. (2007). Differential challenge stressor hindrance stressor relationships with job attitudes, turnover intentions, turnover, and withdrawal behavior: A meta-analysis. Journal of Applied Psychology, 92,438-454.

Richter, A., Tavfelin, S., Sverke, M. (2018). The mediated relationship of leadership on job insecurity. Scandinavian Journal of Work and Organizational Psychology, 3(1), 114, doi: 10.16993/sjwop.43.

Richter, A. (2011). Job Insecurity and Its consequences. Investigating moderators, mediators and gender. Retrieved from https://www.divaportal.org/smash/get/diva2:453238/FULLTEXT01.pdf.

Rosenberg, M. (1965). Society and the adolescent self-image. Princeton, NJ: Princeton University Press. 
Selenko, E., Mäkikangas, A., Mauno, S., \& Kinnunen, U. (2013). How does job insecurity relate to self-reported job performance? Analyzing curvilinear associations in a longitudinal sample. Journal of Occupational and Organizational Psychology, 86, 522-542.

Sharp, G. (2001). The relationship among self-esteem, selfefficacy, and training performance at a GovernmentFunded Nuclear Operations Complex in East Tennessee. [Master's Thesis, University of Tennessee].

Sherer, M., Maddux, J. E., Mercandante, B., Prentice-Dunn, S., Jacobs, B., \& Rogers, R. W. (1982). The self-efficacy scale: Construction and validation. Psychological Reports, $51,663-671$.

Shoss, M.K. (2018). Addressing job insecurity in the 21st Century. Work Science Center Thinking Forward Report Series. Atlanta GA: Georgia Institute of Technology

Shoss, M. K. (2017). Job insecurity: An integrative review and agenda for future research. Journal of Management, 43(6), 1911-1939.DOI: 10.1177/0149206317691574.

Shrout, P. E., \& Bolger, N. (2002). Mediation in experimental and non-experimental studies: new procedures and recommendations. Psychological Methods, 7, 422-445.

Skaalvik, E. M., \& Skaalvik, S. (2010). Teacher self-efficacy and teacher burnout: A study of relations. Teaching and Teacher Education: An International Journal of Research and Studies, 26(4), 1059-1069.

Smith, R.E. (2013). Insecure Commitment and Resistance: An Examination of Change Leadership, Self-Efficacy, and Trust on the Relationship between Job Insecurity, Employee Commitment, and Resistance to Organizational Change. [Unpublished Doctoral Dissertation, University of Minnesota].
Sverke, M., Hellgren J. Näswall, K. (2005). No Security: a Meta-Analysis and Review of Job Insecurity and its Consequences. Journal of Occupational Health Psychology, 7, 242-264.

Sverke, M., Hellgren, J., \& Na“swall, K. (2002). No security: A meta-analysis and review of job insecurity and its consequences. Journal of Occupational Health Psychology, 7, 242-264. doi:10.1037/1076-8998.7.3.242.

Tesser, A. (2000). The encyclopedia of psychology. Behavioral of Science, 3, 213-216.

United States Bureau of Labor Statistics. (2011). Mass layoffs (monthly). Retrieved from http://www.bls.gov/news.release/mmls.toc.htm

Wellman, N., Huang, G., Ashford, S.J., Lee, C., Wang, L. (2016). Deviant and Exit: the Organizational cost of job insecurity and moral disengagement. Journal of Applied Psychology, 4, 1-58. doi: 10.1037/ap10000158.

Wood, R., \& Bandura, A. (1989). Impact of conceptions of ability on self-regulatory mechanisms and complex decision making. Journal of Personality and Social Psychology, 56,407-415.

Wuepper, D., \& Lybbert, T. (2017). Perceived self-efficacy, poverty and economic development. Prepared for Annual Review of Resource Economics 2017.

Keim, A.C., Landis, R.S., Pierce, C.A., \& Earnest, D.R. (2014). Why do employees worry about their jobs? A meta-analytic review of predictors of job insecurity. Journal of Occupational Health Psychology, 19(3):26990. 